\title{
Open-pore film drainage (OFD): a new multipurpose tool for endoscopic negative pressure therapy (ENPT)
}

\section{다(1) $(\div)$}

\author{
Authors \\ Christian Theodor Mueller ${ }^{1}$ \\ Institutions \\ 1 Katholisches Marienkrankenhaus Hamburg gGmbH, \\ Department for General, Abdominal, Thoracic and \\ Vascular Surgery, Hamburg, Germany \\ 2 Westküstenklinikum Heide, Department for Internal \\ Medicine, Gastroenterology, Hemato-Oncology, \\ Nephrology and Endocrinology, Heide, Germany
}

Gunnar Loske ${ }^{1}$, Tobias Schorsch ${ }^{1}$, Frank Rucktaeschel ${ }^{2}$, Wolfgang Schulze ${ }^{1}$, Burkhard Riefel ${ }^{1}$, Vera van Ackeren ${ }^{1}$,

submitted 21.6.2017

accepted after revision 5.3.2018

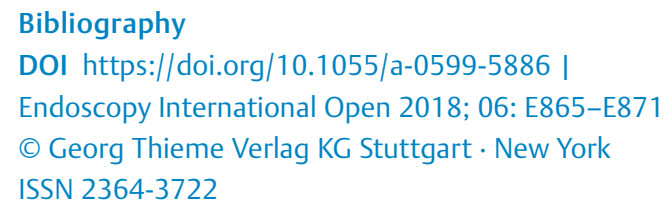

Corresponding author

Dr. med. Gunnar Loske, MD, Katholisches

Marienkrankenhaus Hamburg gGmbH, Department for General, Abdominal, Thoracic and Vascular Surgery, Alfredstrasse 9 Hamburg 22087, Germany

Fax: +49 (0)4025461400

loske.chir@marienkrankenhaus.org

\section{ABSTRACT}

Background and study aims Endoscopic negative pressure therapy (ENPT) has been developed to treat gastrointestinal leakages. Up to now, ENPT has usually been performed with open-pore polyurethane foam drains (OPD). A big disadvantage of the OPDs is their large diameter. We have developed a new, small-bore open-pore film drainage
(OFD). Herein we report our first experience in a case series of 16 patients.

Patients and methods OFD is constructed with a drainage tube and a very thin double-layered open-pore drainage film (Suprasorb CNP, Drainage Film, Lohmann \& Rauscher International, Germany). The distal end of the tube is wrapped with only one layer of film. OFD is placed into the gastrointestinal leakage site with common endoscopic techniques. The tube is connected to an electronic vacuum device and continuous negative pressure of $-125 \mathrm{mmHg}$ applied.

Results From 2013 to 2016, 16 patients were treated with the new OFD device. In 10 patients, transmural intestinal defects (4 esophageal, 4 rectum/colon, 1 duodenal, 1 pancreatic cyst) were closed with ENPT in median time of 12 days (range 3-34 days). Five of the 10 patients were treated solely with OFD devices. In five patients ENPT started with ODP and changed to OFD when the cavity was shrunken to a channel with a small opening. In four patients postoperative gastric reflux was eliminated for 5 to 16 days.

Conclusions Small-bore OFD opens up promising new treatment options within ENPT. OFD can be used in endoscopic closure management of intestinal leakages in the upper and lower gastrointestinal tract. Gastric reflux can be eliminated in an active manner. OFD can be inserted nasally. OFD may be an adequate substitute for OPD, especially when placement of the larger OPD is difficult.

Meeting presentations: The authors' experience was first reported in an oral presentation at the 46th Kongress der Deutschen Gesellschaft für Endoskopie und Bildgebende Verfahren in Mannheim (DGE-BV), 17. - 19.03.2016.

\section{Introduction}

Endoscopic negative pressure therapy (ENPT, synonymous with endoscopic vacuum therapy or EVT) was developed for treatment of complex gastrointestinal leaks, perforations and fistulae. ENPT was originally applied for postoperative rectum conditions such as leaks and perforations [1], but soon its usefulness became evident for treating perforations, leaks and fistulae of the esophagus [2].

Until now ENPT has been performed using drains, which are constructed from open-pore polyurethane foam and a drainage tube (OPD) [3]. In brief, an open-pore polyurethane foam is fixed with sutures at the distal end of a drainage tube ( $\triangleright$ Fig.1). The OPD is then placed endoscopically with a grasper 

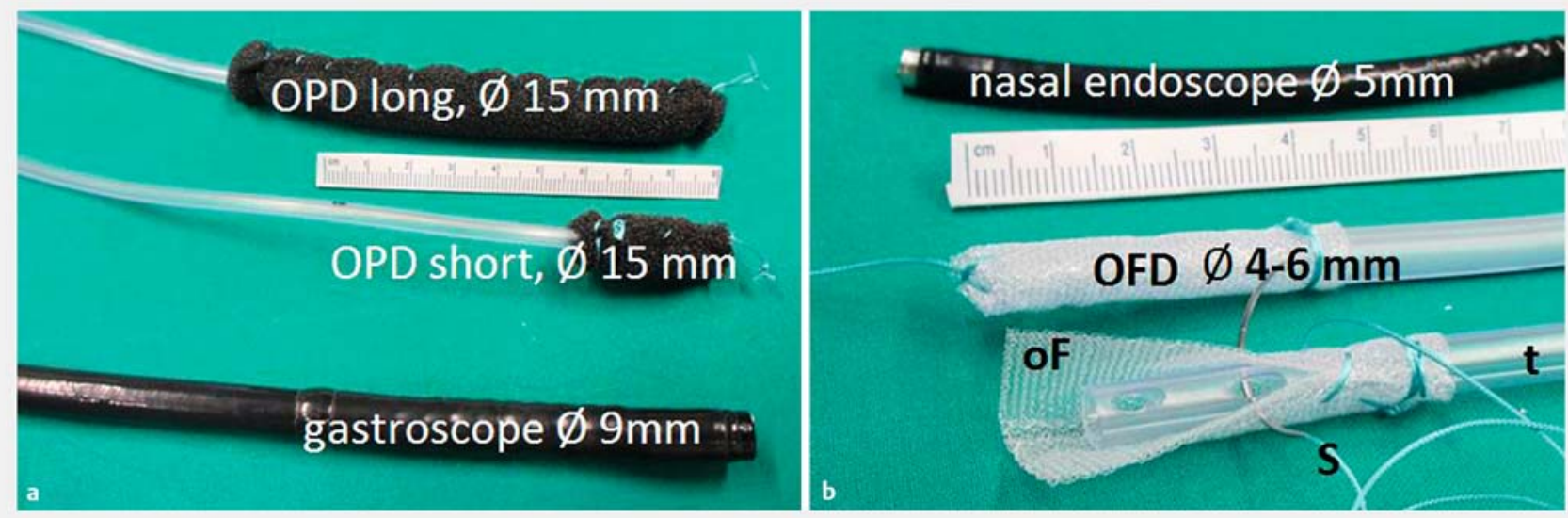

- Fig. 1 Consider the scale. a Open-pore polyurethane foam drainage (OPD), long with 15-mm diameter, is used for intraluminal endoscopic negative pressure therapy (ENPT) in the esophagus; shorter OPD is used for intracavitary ENPT. A standard gastroscope has a 9-mm diameter. b New open-pore film drainage, diameter 4 to $6 \mathrm{~mm}$, construction of OFD with open-pore film (oF), suture (S) and drainage tube (t), nasal endoscope diameter $5 \mathrm{~mm}$

through the defect into an extraluminal cavity (intracavitary ENPT) or intraluminally onto the defect zone (intraluminal ENPT) [4]. Application of negative pressure to the OPD with an electronic vacuum device results in collapsing of the wound cavity and/or intestinal lumen around the polyurethane foam (i. e. distal end of OPD). The constant suction of debris and material along with the collapse of the lumen and rapid fibrin deposition and epithelialization results in secondary wound closure of the defect, while the secretions are constantly suctioned through the drainage tube.

Until recently most OPDs had been self-constructed, but now a commercial system has become available in Europe. However, one potential disadvantage of these devices is a distal diameter of $15 \mathrm{~mm}$ to $30 \mathrm{~mm}$, which hinders endoscopic placement through the hypopharynx and small openings.

We have developed a novel open-pore film drainage (OFD) system for vacuum therapy using open-pore film instead of foam. The major advantage of this system is its smaller distal diameter, making it easier to place and manipulate endoscopically [5-8]. Herein we report our first experience with these small-bore vacuum drainage devices.

\section{Patients and methods}

This is a retrospective, single-center, open-label, consecutive case series using film-based OFD for treatment of gastrointestinal leaks, perforations, fistula and drainage of postoperative reflux. Inclusion criteria included adult patients aged $>18$ years with iatrogenic or natural gastrointestinal leaks, perforations and fistula. Exclusion criteria included pregnancy, non-correctable coagulopathy, and failure or inability to provide informed consent. All patients provided informed consent for the procedure and the study was conducted according to the Helsinki guidelines.

For construction of this OFD, a gastric drainage tube (Ventrol, 12 and $18 \mathrm{Ch} \times 120 \mathrm{~cm}$; Covidien Argyle, Dublin, Ireland)
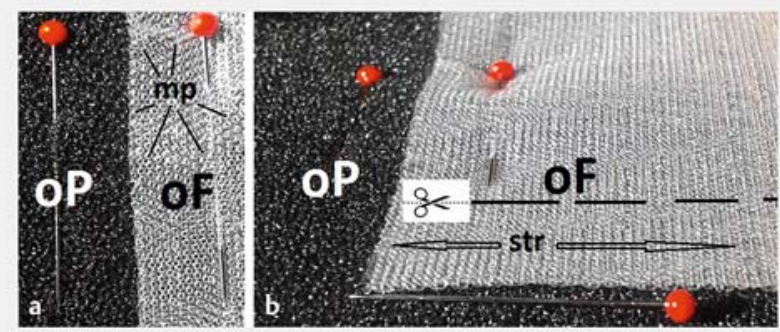

Fig. 2 Open-pore polyurethane foam (OP) and open-pore double layer film (oF) stuck on with a needle. a View from above on the micro pores (mp) of the open-pore film (oF). b Cutting (scissors) a strip (str) of the film for construction of an OFD.

and a very thin double-layered open-pore drainage film (Suprasorb CNP, Drainage Film; Lohmann \& Rauscher International GmbH \&Co.KG, Rengsdorf, Germany) are used ( $\triangleright$ Fig. 1 ).

A commercially available double-layered open-pore drainage film that was developed for abdominal negative pressure treatment was utilized. The film consists of two perforated membranes with a small interspace, which does not collapse when vacuum is applied onto the film. With negative pressure, fluid secretions are guided through and along the film.

To create a single-lumen OFD, a strip of the film $(3 \mathrm{~cm}$ wide and 3 to $25 \mathrm{~cm}$ in length) is cut ( $\triangleright$ Fig. 2). The distal end of the drainage tube is wrapped with the film and fixed by twisting a suture around it ( $\boldsymbol{\vee V i d e o} \mathbf{1}$ and $\boldsymbol{\nabla}$ Fig. $\mathbf{1}$ ). In addition, a loop is formed with the suture at the tip of the tube, which can be grasped with endoscopic forceps to facilitate placement. Small-bore open-pore drains with a single lumen constructed with this method have a diameter of $4 \mathrm{~mm}$ to $6 \mathrm{~mm}$. Thus, insertion through small openings becomes feasible and is easily accomplished. $>$ Table 1 shows the specific data on OPD and OFD. 
- Table 1 Specific data on OPD and OFD.

\begin{tabular}{|c|c|c|}
\hline Data & Open-pore film drainage (OFD) & Open-pore polyurethane foam drainage (OPD) \\
\hline Material & Very thin double layered film membrane & Polyurethane foam \\
\hline Diameter of drainage tube & $4-6 m m$ & $4-6 m m$ \\
\hline $\begin{array}{l}\text { Diameter of distal end of drainage tube } \\
\text { with open-porosity element }\end{array}$ & $4-6 m m$ & $1.5-3.2 \mathrm{~cm}$ \\
\hline $\begin{array}{l}\text { Length of distal end of drainage tube with } \\
\text { open porosity element }\end{array}$ & $3-25 \mathrm{~cm}$ & $3-12 \mathrm{~cm}$ \\
\hline Visible effect of negative pressure & Pimpled pattern & Erosive pattern \\
\hline Endoscopic techniques & $\begin{array}{l}\text { Push, pull, pull-through, guide-wire, Seldinger } \\
\text { technique }\end{array}$ & Push, pull, pull-through \\
\hline Negative pressure therapy variants & Intraluminal and intracavitary & Intraluminal and intracavitary \\
\hline Insertion & $\begin{array}{l}\text { Nasally and through openings smaller than } \\
1.5 \mathrm{~cm} \text { in diameter }\end{array}$ & $\begin{array}{l}\text { Orally and through openings more than } 1.5 \mathrm{~cm} \text { in } \\
\text { diameter }\end{array}$ \\
\hline
\end{tabular}

To allow enteral nutrition during vacuum therapy, OFD drainage can also be constructed as a double-lumen OFD device with intestinal feeding tube. Therefore, the lateral drainage openings of a triluminal tube (FrekaTrelumina, CH/Fr 16/9, 150 cm, Fresenius Kabi AG, Bad Homburg, Germany) were coated with the open-pore film for suction. The ventilation channel of the tube was blocked with a clamp. Furthermore, OFD was made by wrapping the distal end of a urinary balloon catheter, which enabled fixation of the device in a cave by dilatation of the balloon ( $\triangleright$ Fig. 3 ).

The procedure for placing OFD for use in the upper gastrointestinal tract is similar to that for gastroduodenal or intestinal feeding tubes. First, the OFD is inserted nasally and then the tip of the drain is grasped with forceps and pushed forward under direct endoscopic view, which is also our standard technique for the lower gastrointestinal tract. This OFD can be placed intraluminally as well as intracavitary.

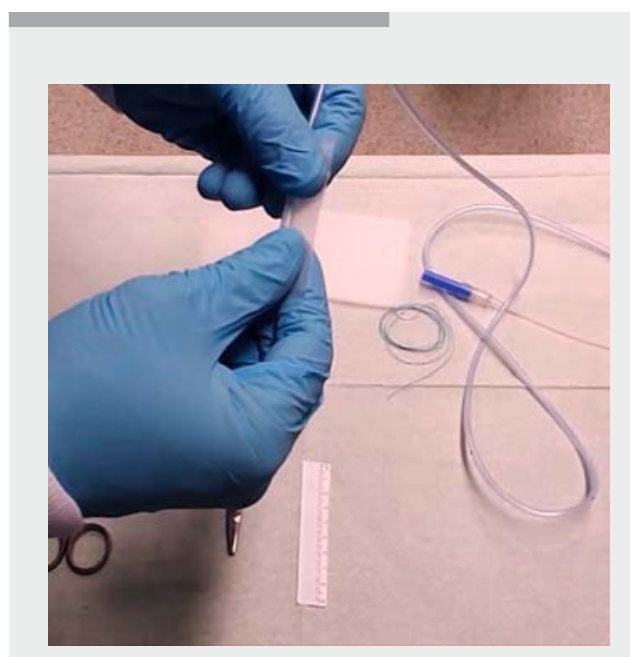

Video 1 Construction of an OFD, demonstration of insertion and removal of an OFD through a small transgastric opening [5] and in a preformed thoracic wound channel.
Alternative placement techniques are insertion using a guidewire or Seldinger technique or positioning by pullthrough maneuver [9]. OFD is removed by pulling on the proximal part of the drainage tube, complete removal being assured by endoscopic inspection.

For the placement procedure, we use a standard gastroscope and $\mathrm{CO}_{2}$ insufflation. To avoid dislocation, we prefer to check the correct position using a small-bore nasal endoscope. Vacuum is applied to the drainage tube using an electronic vacuum device (KCI V.A.C. Freedome, KCI USA Inc., San Antonio, Texas, United States). In all cases, we used our standard negative pressure of $-125 \mathrm{mmHg}$ for endoscopic vacuum therapy with continuous suction to drain fluids in an active manner.

\section{Results}

From 2013 to 2016 we treated 16 patients with ENPT using the new OFD system. The following regions or organs were treated: esophagus $(4 \times)$, rectum/colon $(4 \times)$, stomach $(4 \times)$, pancreatic cyst $(1 \times)$, duodenum $(1 \times)$ and complicated wounds $(2 \times)$. A $120-\mathrm{cm}$-long drainage tube was adequate for treatment. The length of the film drainage segment of the tube was adapted according to the length of the inner wound. To eliminate gastric reflux, the segment was up to $25 \mathrm{~cm}$ long. For duodenal, gastric and esophageal treatment, the tube was inserted directly through the nose, similar to a gastroduodenal tube.

In 10 patients transmural intestinal defects (4 esophageal, 4 rectum/colon, 1 duodenal, 1 pancreatic cyst) were closed with ENPT in a median time of 12 days (range 3-34 days). Five of 10 patients were treated solely with OFD devices. In five patients ENPT started with ODP and then changed to OFD when the cavity was shrunken to a channel with a small opening.

In detail, four leaks in the esophagus (two after Ivor-Lewis esophagectomy, one after gastrectomy and one patient with Boerhaave's perforation [7]) were healed with ENPT. In three patients ENPT started with OPD. After shrinkage to a small channel, the last treatment period was done with a single-lumen OFD. In one patient with a small opening, therapy was 

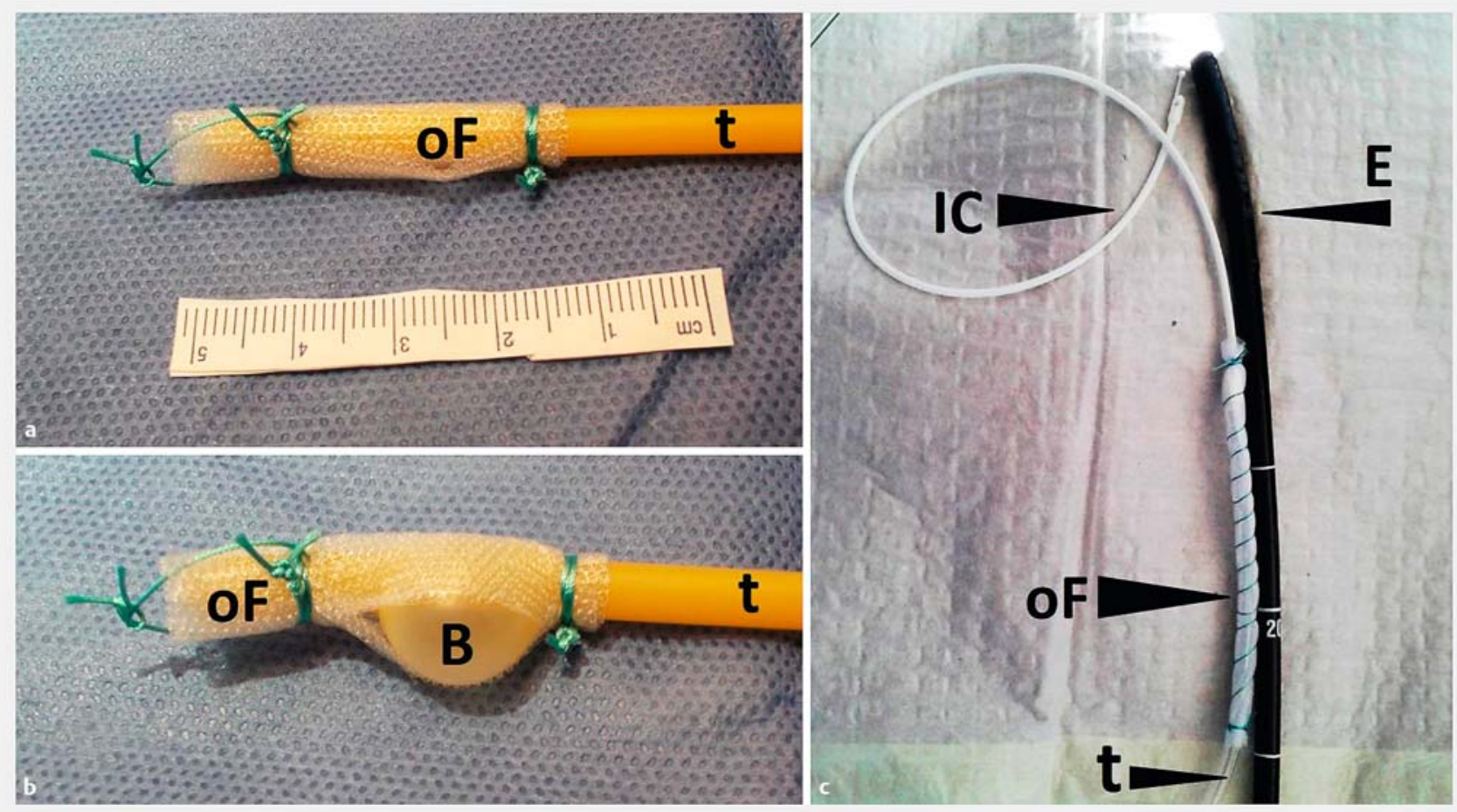

- Fig. 3 Variants of OFD. a Open-pore film (oF) is wrapped around the tip of a balloon catheter (t). b Filled balloon. c Construction of a double-lumen OFD with a gastric channel ( $\mathrm{t}$ ) wrapped with an open-pore film (oF) and an intestinal feeding channel (IC), endoscope (E).

done solely with an OFD. The treatment period with OFD was 4 to 6 days. All leaks were closed after ENPT in 6 to 34 days total.

In the rectum, OFD was used in three patients (1 leakage and 1 fistula) after anterior rectal resection and one perforation after hemorrhoidopexy and in the colon in one patient in a case of anastomotic leak after resection of sigmoid. In two patients ENPT started with OPD. After shrinkage to a small channel, the last treatment period was done with a single-lumen OFD-device. In one patient, a perforation after stapled hemorrhoidopexy was treated with single-lumen OFD. In one patient, an anastomotic fistula after rectum resection was treated with a balloon-OFD device. Treatment period with OFD was 3 to 13 days. All leaks in the rectum and colon were closed.

In one case of duodenal perforation after ERCP, duodenal secretions were drained intraluminally with negative pressure [6]. In that case, a complementary diagnostic laparoscopy was done, but no operative closing procedure was necessary. A single-lumen OFD-device was used for 6 days and then the defect healed.

In one patient, OFD was used to drain an infected pancreatic cyst after transgastric necrosectomy to shrink and collapse the persisting retro-gastral cavity [5]. A single-lumen OFD was inserted transgastrically; the cyst collapsed completely and healed after 10 days of treatment with ENPT.

Using the smaller diameter of the OFD compared to the OPD, we switched to OFD when shrinking wound openings led to wound cavities that still needed treatment. Generally, we terminated therapy when the wound cavity was covered with granulation tissue and self-cleaning. In the case of small wound openings, the latter can lead to prolonged therapy as fluid retention may reactivate wound inflammation and thus become a septic focus.

In four patients, OFD-devices were placed to drain increased postoperative reflux in an active manner. The aim was to empty the stomach completely in patients who suffered from therapyrefractory aspirations postoperatively. In two patients, we used single-lumen drains and in two patients, double-lumen OFD with an enteral feeding tube, which enabled simultaneous enteral nutrition. In all patients, reflux was eliminated completely for 5 to 16 days with negative pressure.

In two patients, EVT with OFD was done in cases of complicated wound infection. One patient had an infected sacral wound after rectum extirpation and the other had complicated wound healing after colostomy. In both cases, ENPT started with OPD and changed to OFD. Treatment duration was 14 days in total; 7 and 10 days, respectively, for OFD.

In 11 patients, OFD was used for intracavitary ENPT and in five patients, it was used for intraluminal drainage.

- Table 2 shows details of ENPT with OFD devices.

In general, after application of vacuum with an electronic vacuum device, OFD drains fluid liquids (wound secretions, gastric juices, duodenal secretions) well in an active manner. Viscous saliva or feces block the pores of the film similar to the OPD foam.

We did not observe any complications related to use of OFD. Compared to an OPD with negative pressure, an OFD did not 
- Table 2 Data on ENPT with OFD.

\begin{tabular}{|c|c|c|c|c|c|c|c|}
\hline $\begin{array}{l}\text { Region of } \\
\text { treatment }\end{array}$ & $\begin{array}{l}\text { Diagnosis and reason } \\
\text { for treatment with } \\
\text { ENPT }\end{array}$ & $\begin{array}{l}\text { Type of OFD (sin- } \\
\text { gle lumen (SL), } \\
\text { double lumen } \\
\text { (DL), balloon (B) }\end{array}$ & $\begin{array}{l}\text { Negative } \\
\text { pressure } \\
(-\mathrm{mmHg})\end{array}$ & $\begin{array}{l}\text { Total } \\
\text { duration } \\
\text { of ENPT } \\
\text { (d) }\end{array}$ & $\begin{array}{l}\text { ENPT } \\
\text { Duration } \\
\text { with OFD } \\
\text { (d) }\end{array}$ & $\begin{array}{l}\text { ENPT } \\
\text { with } \\
\text { OFD } \\
\text { alone' (n) }\end{array}$ & $\begin{array}{l}\text { ENPT with OFD } \\
\text { complimentary or } \\
\text { consecutive with } \\
\text { OPD (n) }\end{array}$ \\
\hline $\begin{array}{l}\text { Esophagus } \\
n=4\end{array}$ & $\begin{array}{l}1 \times \text { Boerhaave's syn- } \\
\text { drome [7], } 3 \times \text { anasto- } \\
\text { motic leakages }(2 \times \text { Ivor- } \\
\text { Lewis esophagoectomy, } \\
1 \times \text { gastrectomy) }\end{array}$ & SL, DL & 125 & $6-34$ & $3-6$ & $1 \times$ & $3 x$ \\
\hline $\begin{array}{l}\text { Rectum } \\
n=3\end{array}$ & $\begin{array}{l}1 \times \text { anastomotic leakage } \\
\text { and } 1 \times \text { fistula after rec- } \\
\text { tum resection, } 1 \times \text { per- } \\
\text { foration after haemor- } \\
\text { rhoidopexy }\end{array}$ & SL, B & 125 & $3-26$ & $3-13$ & $2 x$ & $1 \times$ \\
\hline $\begin{array}{l}\text { Colon } \\
n=1\end{array}$ & $\begin{array}{l}1 \times \text { anastomotic leakage } \\
\text { after resection of sig- } \\
\text { moid }\end{array}$ & SL & 125 & 6 & 3 & - & $1 \times$ \\
\hline $\begin{array}{l}\text { Stomach } \\
n=4\end{array}$ & $\begin{array}{l}\text { Increased postopera- } \\
\text { tive reflux ( } 1 \times \text { gastro- } \\
\text { jejunostomy, } 1 \times \text { gastro- } \\
\text { pancreaticostomy, } 2 \times \\
\text { Whipple operation })\end{array}$ & SL, DL & 125 & $5-16$ & $2-16$ & $3 x$ & $1 \times$ \\
\hline $\begin{array}{l}\text { Duodenum } \\
\mathrm{n}=1[6]\end{array}$ & $\begin{array}{l}1 \times \text { perforation after } \\
\text { ERCP }\end{array}$ & $S L$ & 125 & 6 & 6 & $1 \times$ & - \\
\hline $\begin{array}{l}\text { Pancreas } \\
\mathrm{n}=1[5]\end{array}$ & $\begin{array}{l}1 \times \text { infected pancreatic } \\
\text { cyst }\end{array}$ & $S L$ & 125 & 10 & 10 & $1 \times$ & - \\
\hline $\begin{array}{l}\text { Superficial } \\
\text { wound } \\
n=2\end{array}$ & $\begin{array}{l}\text { Complicated wound } \\
\text { healing }(1 \times \text { colostoma, } \\
1 \times \text { infected sacral cav- } \\
\text { ity) }\end{array}$ & $S L$ & 125 & 14 & 7,10 & - & $2 x$ \\
\hline
\end{tabular}

adhere to the tissue to the same degree. An indication of the correct function of suction is a typical "pimpled" pattern on the tissue in contact with the film ( $\mathbf{F i g . 4}$ ). With negative pressure, the tissue in contact with the film is sucked into the pores of the open-pore film. The resulting pattern resembles small nipples. When the suction was stopped, this pattern disappeared within a few hours.

\section{Discussion}

In this study, we demonstrated that a novel small-bore OFD is a promising new treatment option for patients with complex gastrointestinal leaks and perforations. This thin membrane, smallbore drainage system can be placed easily and effectively in all patients, including those in whom traditional OPD is impossible. An attractive aspect of our OFD system is the feasibility of nasal insertion, similar to a gastric tube. Therefore, OFD may be an adequate addition or even substitute for OPD, especially when placement of the larger OPD is difficult or impossible or it has failed.

In the past few years, endoscopic negative pressure therapy with OPD has become one of the most interesting endoscopic methods to treat anastomotic, spontaneous and iatrogenic gas- trointestinal leaks [10]. To date, 210 patients have been reported in 11 retrospective studies for treatment of esophageal leaks with a success rate of $90 \%$ healing [11]. Recently, Neumann et al. demonstrated a first case series with successful endoscopic treatment of mucosal ischemia following esophagectomy [12]. Leeds et al. reported on a first case series of nine patients treated with ENPT for staple line leaks after laparoscopic sleeve gastrectomy [13]. In addition, new treatment indications and techniques have been found for leaks of the duodenum, pancreas, stomach, colon and biliary system [14-16].

The newly developed OFD system has the major advantage of small distal diameter, which allows for easy endoscopic insertion, maneuverability and positioning. The length of the openpore film element can be adapted according to local circumstances; we used $3-\mathrm{cm}$ to $25-\mathrm{cm}$ segments. Importantly, liquid fluids such as biliary, duodenal, and gastric secreta and wound edema around the vacuum drainage are removed in an active manner through and along the pores of the covering film.

Therefore, this tubing has advantages for use as a primary or secondary drainage system. When using this system as a primary drainage method, it can be placed into the gastrointestinal lumen around a small perforation or leak or inside a cavity with small-diameter access. Bile is well known to have a deleter- 


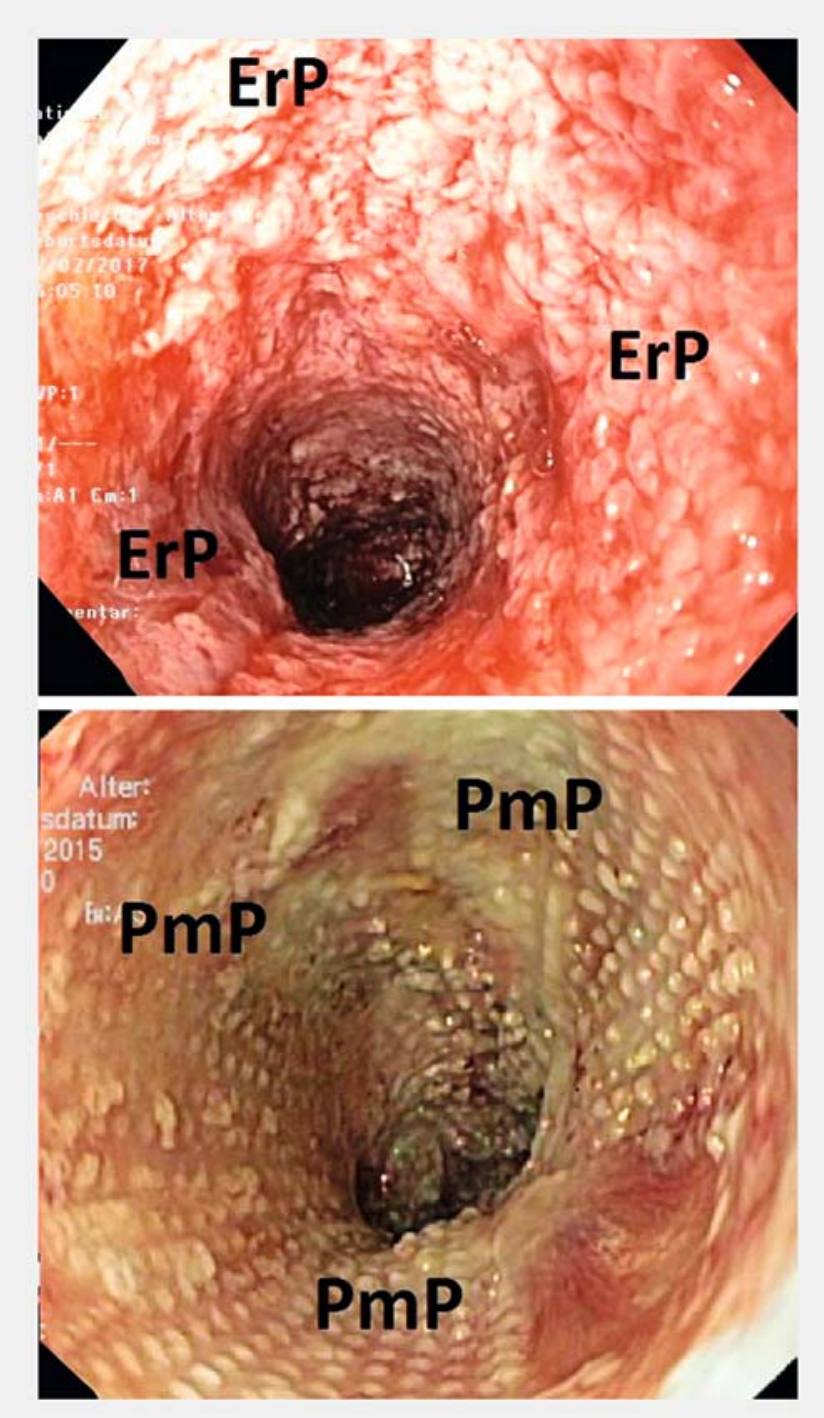

> Fig. 4 Typical pattern on the tissue treated with ENPT. Suction patterns are a sign of good function of ENPT. a Endoscopic view with a standard gastroscope of a shrunken wound channel with erosive patterns (ErP) after removal of an OPD. b Endoscopic view with a small-bore nasal endoscope of a shrunken wound channel with pimpled patterns after removal of an OFD.

ious effect on wound healing. Therefore, this OFD system can be used as an adjunct after closing upper endoluminal gastrointestinal perforations or for prophylactic drainage after an extensive endoscopic submucosal dissection. In contrast to traditional nasogastric tubes with large suctioning holes which can further damage the neighboring mucosa, the micro-pore film will not damage the surrounding tissue. The open-pore function of the new drainage seems to be similar to an OPD. However, there is a big difference in the suctioning mechanism. From our clinical experience and that of other experts we know that conventional suction tubes used for open pore drainage, such as wound drains or catheter with large lateral openings get blocked sooner or later when a vacuum of $125 \mathrm{mmHg}$ is applied. In addition, tissue is often sucked into the lateral openings of these suctioning tubes. The current material differs from the open-pore film or foam material in that the flat suctioning mechanism is present along the entire surface of the film or foam. The film-wrapped tip of the drainage adheres onto the tissue via suction. Therefore, even if some of the pores are blocked, suction is still maintained along the whole surface of the film because of the open-pore communication of the pores and the small interspace between the membranes. This is a major difference for small-bore conventional wound drainage or gastric tubes, which can become blocked with negative pressure application.

The main advantage of the OFD is its small diameter, which enables insertion through the nose similar to a gastric or intestinal feeding tube. Because placement through small openings was easy, new applications of OFD are possible, such as for urinary vacuum therapy [8].

Recently two cases of severe bleeding with use of traditional, sponge-based intracavitary OPD in the esophagus [17] and ingrowth and device disintegration [18] have been described. OPD can adhere to the tissue with negative pressure; in contrast we found that OFD does not become so adhered. This may be explained by the regular spacing of pores in the film. Further development may lead to use of the drainage film to cover sponge-based OPD, as proposed by Wallstabe et al. [15]. Nevertheless, only larger experience with OFD and comparative studies will show which system has the least number of adverse events.

One limitation of any endoscopic vacuum method is the prerequisite for establishment and maintenance of continuous suction. Therefore, electronically controlled vacuum devices and awareness of the endoscopic signs of effective therapy are necessary. Interruption of therapy caused by malfunction of the electronic device, dislocation of the film and blockage of film or tube must be always avoided. After removing the OFD, the typical appearance of a pimpled pattern should be seen on the tissue in contact with the drainage.

Therefore, physicians and nursing staff need to be carefully trained in vacuum therapy. A non-working vacuum drainage can be a septic focus as interruption of the system may be hazardous for the patient. Other limitations are passage of the tubes through the nose, anus or wound openings, which could lead to local discomfort. At a minimum, negative pressure therapy is a surgical treatment for inner wounds. Given the need for regular endoscopic monitoring of wound healing and system changes, the number of endoscopic examinations will rise.

We would like to mention potential limitations of this study. First, the study was relatively small. However, it is the largest experience using small-bore OFD published so far. The insights gained from our experience should allow for design of a larger prospective comparative study. Second, this was an open-label, observational feasibility study. Based on the current study, we do not have evidence of clinical superiority. However, that will be pursued with future studies. Nevertheless, we believe that because of its simplified design and advantageous suctioning membrane-mechanism, this system holds much promise for treatment of leaks and perforations. Third, the endoscopists that participated in this study are experts in the field of thera- 
peutic endoscopy. However, expertise in therapeutic endoscopy is widespread and the technique and results should be easily reproducible in similar centers elsewhere.

\section{Conclusion}

In summary, small-bore OFD opens up promising new treatment options within ENPT, including in patients in whom traditional OPD has failed. Use of OFD in ENPT seems to have broad applications. Furthermore, this tube can be inserted nasally similar to a gastric tube. Therefore, OFD may become an adequate complement to or substitute for OPD, especially when placement of the larger OPD is difficult or impossible.

Prospective, multicenter, randomized studies comparing OPD and OFD are warranted.

\section{Acknowledgements}

The authors thank Prof. Klaus Mönkemüller for assistance in editing the manuscript. They also thank the nursing staff of the interdisciplinary endoscopic unit of Marienkrankenhaus Hamburg for their excellent technical assistance and colleagues from the intermediate care unit for their cooperation.

\section{Competing interests}

Gunnar Loske is consultant for Lohmann \& Rauscher GmbH \& Co.KG.

\section{References}

[1] Weidenhagen R, Gruetzner KU, Wiecken T et al. Endoscopic vacuumassisted closure of Anastomotic leakage following anterior resection of the rectum: a new method. Surg Endosc 2008; 22: 1818-1825

[2] Loske G, Schorsch T, Muller C. §\#/ITL\#§ Endoscopic vacuum sponge therapy for esophageal defects. Surg Endosc 2010; 24: 2531-2535

[3] Mennigen R, Senninger N, Laukoetter MG. Novel treatment options for perforations of the upper gastrointestinal tract: Endoscopic vacuum therapy and over-the-scope clips. Gastroenterol 2014; 20: $7767-7776$

[4] Loske G, Schorsch T, Müller C. Intraluminal and intracavitary vacuum therapy for esophageal leakage: a new endoscopic minimally invasive approach. Endoscopy 2011; 43: 540-544
[5] Loske G, Schorsch T, Gobrecht O et al. Transgastric endoscopic vacuum therapy with a new open-pore film drainage device in a case of infective pancreatic necrosis. Endoscopy 2016; 48: E148 - 149

[6] Loske G, Rucktäschel F, Schorsch T et al. Successful endoscopic vacuum therapy with new open-pore film drainage in a case of iatrogenic duodenal perforation during ERCP. Endoscopy 2015; 47: E577E578

[7] Loske G, Schorsch T, van Ackeren V et al. Endoscopic vacuum therapy in Boerhaave's syndrome with open-pore polyurethane foam and a new open-pore film drainage. Endoscopy 2015; 47: E410 - 411

[8] Loske G, Schorsch T, Kiesow RU et al. First report of urinary endoscopic vacuum therapy: For large bladder defect after abdominoperineal excision of the rectum. Video paper. Chirurg 2017; 88: $42-47$

[9] Loske G, Liedke M, Schlöricke E et al. Endoscopic negative-pressure therapy for duodenal leakage using new open-pore film and polyurethane foam drains with the pull-through technique. Endoscopy 2017; 49: E300-E302

[10] Kuehn F, Janisch F, Schwandner F et al. Endoscopic Vacuum Therapy in Colorectal Surgery. J Gastrointest Surg 2016; 20: 328-334

[11] Kuehn F, Loske G, Schiffmann L et al. Endoscopic vacuum therapy for various defects of the upper gastrointestinal tract. Surg Endosc 2017; 31: $3449-3458$

[12] Neumann PA, Mennigen R, Palmes D et al. Pre-emptive endoscopic vacuum therapy for treatment of anastomotic ischemia after esophageal resections. Endoscopy 2017; 49: 498-503

[13] Leeds SG, Burdick JS. Management of gastric leaks after sleeve gastrectomy with endoluminal vacuum (E-Vac) therapy. Surg Obes Relat Dis 2016; 12: $1278-1285$

[14] Fischer A, Thimme R, Hopt UT et al. Two-sided sponge (TSS) treatment: Description of a novel device and technique for endoscopic vacuum treatment (EVT) in the upper gastrointestinal tract. Endosc Int Open 2016; 4: E937-E940

[15] Wallstabe I, Tiedemann A, Schiefke I. Endoscopic vacuum-assisted therapy of infected pancreatic pseudocyst using a coated sponge. Endoscopy 2012; 44: E49-E50

[16] Loske G, Aumiller ], Rucktäschel F et al. Spontaneous perforation of an intramural esophageal pseudodiverticulosis treated with intraluminal endoscopic vacuum therapy using a double-lumen vacuum drainage with intestinal feeding tube. Endoscopy 2016; 48: E154 -E155

[17] Laukoetter MG, Mennigen R, Neumann PA et al. Successful closure of defects in the upper gastrointestinal tract by endoscopic vacuum therapy (EVT): a prospective cohort study. Surg Endosc 2017; 31: $2687-2696$

[18] Schniewind B, Schafmayer C, Both M et al. Ingrowth and device disintegration in an intralobar abscess cavity during endosponge therapy for esophageal anastomotic leakage. Endoscopy 2011; 43: E64-E65 